\title{
Design and implementation of a series switching SPSI for PV cell to use in carrier based grid synchronous system
}

\author{
Tawfikur Rahman, S. M. A. Motakabber, Muhammad I. Ibrahimy, A. H. M. Zahirul Alam \\ Department of Electrical and Computer Engineering, International Islamic University Malaysia, Malaysia
}

\begin{tabular}{|c|c|}
\hline Article Info & ABSTRACT \\
\hline Article history: & \multirow{11}{*}{$\begin{array}{l}\text { A carrier-based grid synchronous method is proposed to develop the system } \\
\text { efficiency, phase and power quality of the inverter output waves. The } \\
\text { operating principle of a single-phase phase synchronous inverter (SPSI) is } \\
\text { introduced, with proper synchronous paid to the switching-frequency } \\
\text { synchronizing voltage made by the interleaved process, as well as actual } \\
\text { mitigation approaches. In the construction of the SPSI, input and output } \\
\text { filters are electrically coupled with the two sides of an inverter. The inverter } \\
\text { power electronic switches and other electrical components are operated by } \\
\text { carrier-based grid synchronous controller (CBGSC) with PWM regulator. } \\
\text { The SPSI is designed and implemented with the Toshiba } 40 \mathrm{WR} 21 \text { IGBT, } \\
\text { Digital Microcontroller pulse controller (DMPC) and } 4 \mathrm{~N} 35 \text { Optocoupler with } \\
\text { a fundamental frequency of } 50 \mathrm{~Hz} \text {. The other parameters are considered as } \\
\text { load resistance, } R_{L}=11 \Omega \text {, duty cycle, } 85 \% \text {, carrier frequency, } 2.5 \mathrm{kHz} \text { and } \\
\text { input DC voltage, } \pm 340 \mathrm{~V} \text {. In addition, LCL lowpass grid filters are used to } \\
\text { convert squire wave to sine wave with required phase and frequency. Finally, } \\
\text { the simulated and experimental results obtained with a carrier-based grid } \\
\text { synchronous SPSI experimental prototype are exposed for justification, } \\
\text { showing the phase error of } 55 \% \text { improvement, reduced } 11 \% \text { of THD and the } \\
\text { conversion efficiency of } 97.02 \% \text { highly predicted by the proposed design } \\
\text { technique to improve the microgrid system. }\end{array}$} \\
\hline Received Jan 5, 2019 & \\
\hline Revised Feb 13, 2019 & \\
\hline Accepted Mar 1, 2019 & \\
\hline Keywords: & \\
\hline CBGSC & \\
\hline Efficiency & \\
\hline Grid LCL filter & \\
\hline Input LC Filter & \\
\hline & \\
\hline S-PSI & \\
\hline
\end{tabular}

Copyright (C) 2019 Institute of Advanced Engineering and Science. All rights reserved.

\footnotetext{
Corresponding Author:

Muhammad I. Ibrahimy,

Department of Electrical and Computer Engineering,

International Islamic University Malaysia,

Kulliyah of Engineering, 53100 Jalan Gombak, Kuala Lumpur, Malaysia.

Email: ibrahimy@iium.edu.my
}

\section{INTRODUCTION}

SPSI active carrier-based pulse width modulation (PWM) DC to AC inverters is generally utilized as a means of improving efficiency and developing the power quality of the source current, as the characteristic a higher effective performance compared to their multi-carrier PWM based DC to AC inverter counterparts. In consequence, traditional carrier-based PWM inverters have become dominant in the grid synchronize system, a high-quality further maintained by their characteristic simplicity. Nevertheless, if superior performance is sought, carrier-based PWM inverters denote a better solution to operate lower switching frequency [1]. This type of control mechanism is gradually being implemented in these systems, a trend that is built easier by the current availability of combined power electronic semiconductor switching modules in different control DC to $\mathrm{AC}$ inverter configurations.

Single phase inverters can be operated in discrete, continuous and phasor power flow methods. Among discrete methods, one of the standard methods is the single-phase midpoint source voltage source inverter which uses discretization of the electrical power system for a solution at fixed time steps [2]. On the hand, the configuration of the solver depends on the option which is selected discrete mode to perform a discretization of the model and specify the sample time in the sample time parameter. A multi-carrier based 
PWM phase terminal implementation with two switches the input DC source voltage and two devices in AC-switches arrangement half the input DC source voltage [3]. Continuous and phasor methods are used to perform a continuous and phase solution of the inverter, at the specified by the phasor frequency parameter. If the power inverter switching blocks utilizing ideal switches. This parameter can be visible only when the type of the parameter is set to continuous. By default, this selection is not designated, a large amount of switching ripple current is amplified in the output side that can be affected by the DC bus voltage. In this case, current ripple can be generated low frequency and degrade the power density and quality. For instance, ripple current is degrading the regulator in the solar system [4]; it will be reduced the power quality and lifetime of fuel cells in Gencell [5]; it may be boosted battery storage uninterrupted power systems. Conventionally, the solar power is an unlimited power source that is produced by a PV cell must convention instantaneously and required the bulky size of battery cells. It is a high cost and complexed maintaining issue. To overcome this problem, several cells of the PV modules are connected through common local networks knowing as the grid system [6]. These systems have some limitation. The main drawback is required to take steps to ignore the low-frequency current ripple flowing in the input DC supply, phase synchronization, high preliminary cost, and a large area. Therefore, carrier-based grid synchronous PSI using renewable power system is superior performance and economical.

To illustrate multifunction topology of the single-phase inverter low-frequency supply distorted current has been introduced in the earlier publications [7]. However, the grid filter circuit can be involved to decrease the low-frequency distorted current. For example, DC bus capacitance is improved in [8], and grid filter is injected to DC bus in [9]. Besides, it is more complexed to maximize the weight and size of the DC bus capacitor. An alternative realization of the latter is the S-PSI topology is included a suitable switching circuit and logic controller are diverted to added storage mechanism [10]: traditional buck-boost DC to DC converter is connected to DC bus and process as an input LC filter of active power in [11]; The discussion [12] carried out an exceptional low-frequency distorted compensator that can be sequenced with the novel inverter; A secondary phase terminal is involved in [13], and the total power from DC bus can retain constant by properly monitoring the existing of further phase terminal. Whereas these methods can be successfully overpowering the input frequency ripple current, the additional switches circuit may be led to an increase in cost, power losses and regulator effort.

A switching technique to further develop the system efficiency and increase a power inverter is to utilize series switches. In the latter case, unknown gate signals of the equivalent switches of each phase terminal are interleaved, both the inverter power quality and efficiency are improved [14]. Precisely, the higher harmonic frequency cancellation gain between the interleaved of the half phase terminals consents for the utilize of lower switching frequencies, whereas simultaneously falling the input power quality size and electromagnetic interference filters [15]. It is then expected that an interleaved n-channel Vienna-type rectifier [16] would feature even higher efficiency and power density than its single-channel embodiment. In search of a topology with an efficiency exceeding $99 \%$ that could eliminate the need for active cooling, this work adopted a two-channel interleaved Vienna-type rectifier. It is predictable than that a carrier base synchronous series switching DC to AC inverter depends on switching logic operation would feature even higher overall system performance and power quality than its conventional DC to AC inverter embodiment. In an exploration of a switching topology with a control, the approach is very complicated when since the electromechanical concert, and not appropriate for the power supply systems. Authors in [17] studied that single-phase inverter can be boosted along with incontrollable low-frequency ripple. In this case, the constant duty factor is assumed for the boost stage that is primarily an open-loop voltage regulator. The effect of DC ripple current reduction, fully depends on the DC bus capacitors; thus, filter components of the bus capacitance must comparatively large $[18,19]$.

This paper presents the design and implementation of a carrier-based grid synchronous controller, series switching S-PSI with proper grid synchronous less than lower phase angle. This is more essential to reduction ripple, reduce switching loss and higher efficiency. The inverter operation is maximized for phase voltage of $230 \mathrm{~V} \mathrm{AC}, 45-55 \mathrm{~Hz}$ of a fundamental frequency, line frequency around of $250 \mathrm{~Hz}$ to $500 \mathrm{~Hz}, \mathrm{DC}$ bus voltage $\pm 340 \mathrm{~V} \mathrm{DC}$ and $85 \%$ of duty factor. In addition, grid LCL filter is utilized to couple inverter, convert the signal and reduce the harmonic. This paper is systematized as follows: Section II shows the operating principles of the series switching S-PSI; Section III presents the model configuration and analysis; Section IV presents a design procedure of a switching gate controller; Section V presents grid couple lowpass LCL filter design; Section V presents the grid synchronous method; Section VI presents simulated result and discussion; Section VII presents the experimental results and discusses; and lastly, Section VIII introduces the conclusions drawn from this work. 


\section{OPERATION PRINCIPLES OF THE SERIES SWITCHING S-PSI}

Figure 1 shows the switching topology of the series switching S-PSI configuration. In this system, upper switches (IGBT1, IGBT1a), lower switching (IGBT2, IGBT2a) and flywheel diode connected to the IGBT switch $\mathrm{D}_{1}$ and $\mathrm{D}_{2}$ from a half phase sub-inverter which can operate simultaneously. The remaining switching pairs upper switches IGBT3, IGBT3a, lower switching (IGBT4, IGBT4a) and their corresponding diodes $D_{3}$ and $D_{4}$ from a second-half sub-inverter. The inverter output phase legs are connected utilizing the grid LCL filter input side inductor of $L_{i n v_{-} o}$ and output side inductor of $L_{M G_{-} o}$ is coupled to grid load as seen in Figure 1.

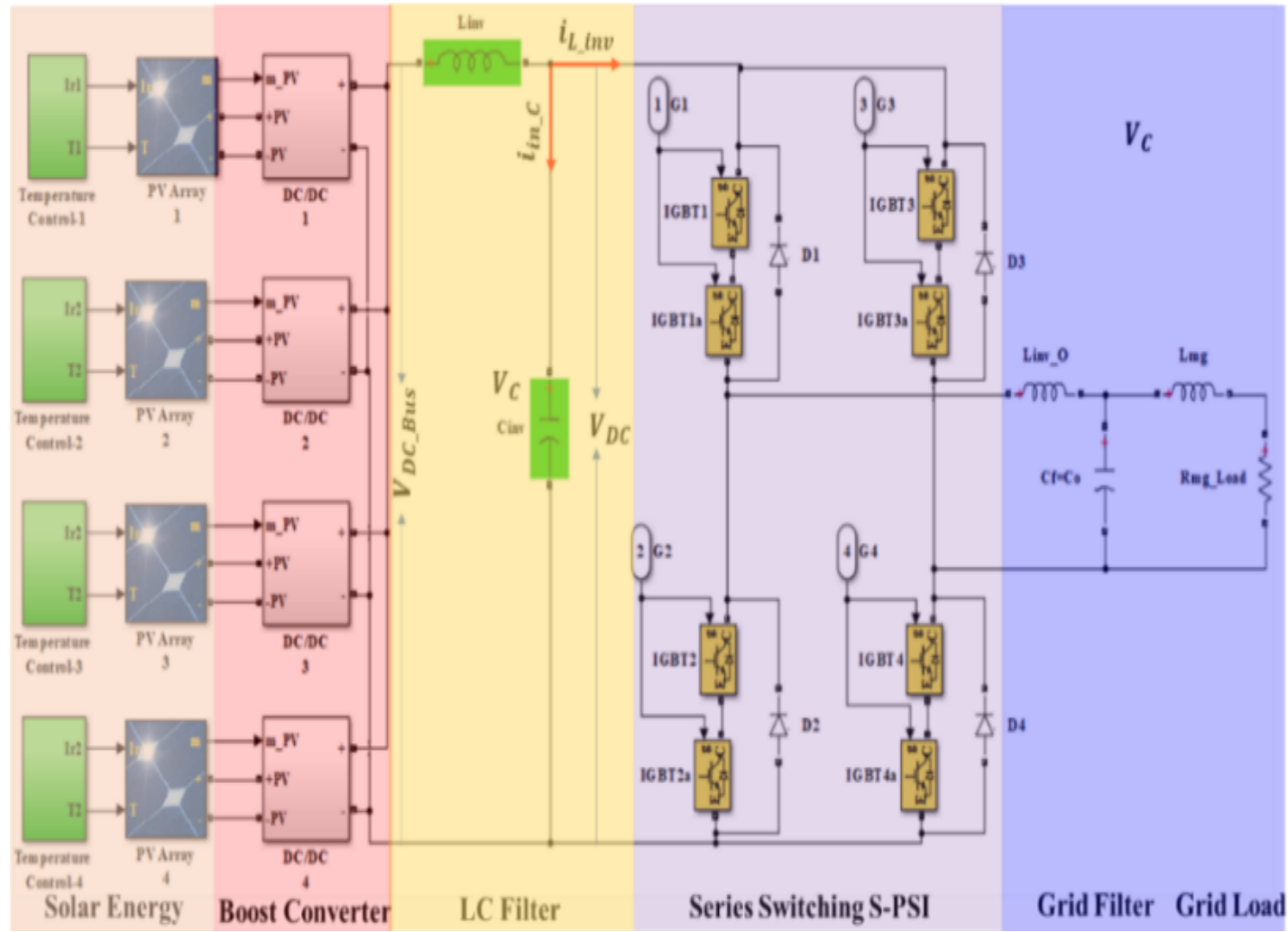

Figure 1. Proposed series switching SPSI circuit configuration [1]

The series switching S-PSI is a voltage source current-commutated inverter, which can be, the devices which commutate at any upper switching or lower switching instant are measured by the instantaneous direction of flow load current. If the load current flow in Figure 2 is positive, the computation will take place between upper switch of $\mathrm{S}_{1}$, lower switch of $\mathrm{S}_{4}$ and $D_{1}-D_{4}$ whereas the lower switch of $\mathrm{S}_{2}$ and upper switch $S_{3}$ are turned OFF. Therefore, the voltage potential at point of phase leg $\mathrm{V}_{a o}$ with reference to the center point of the input DC source will be either half of the DC bus voltage, when $S_{1}-S_{4}$ or $\mathrm{S}_{3}-\mathrm{S}_{2}$ are turned $\mathrm{ON}$ or OFF. 


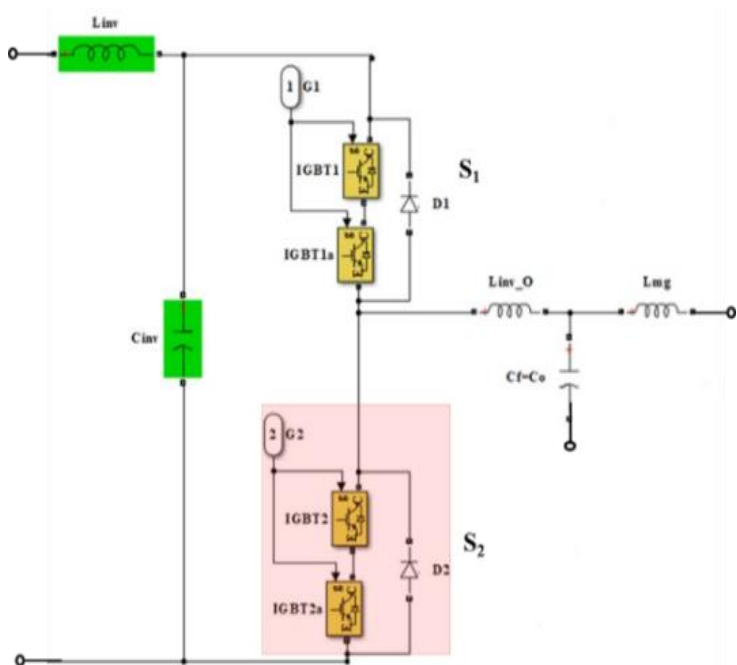

(a)

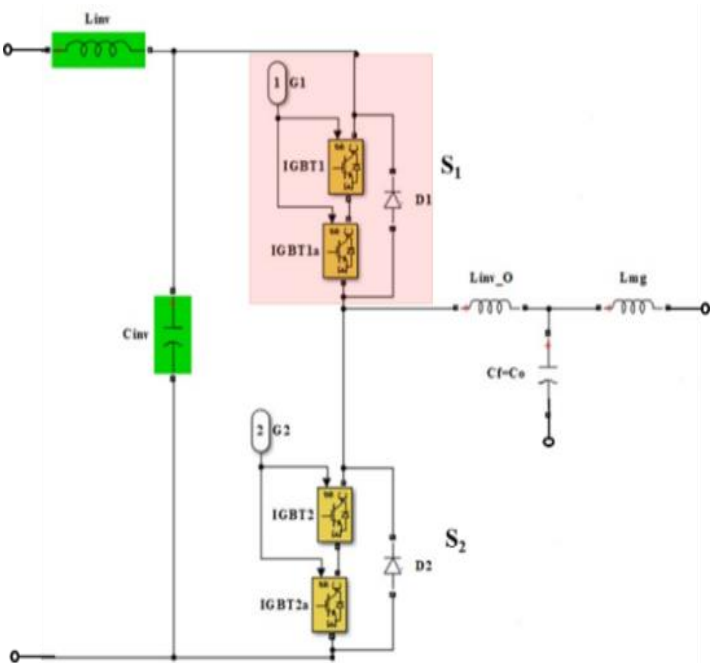

(b)

Figure 2. MATLAB circuit for switching mechanism

\section{MODEL CONFIGURATION AND ANALYSIS}

To work the inverter in series switching method, a phase angle shift is offered between the carriers based PWM of the two-half phase inverter that compound it [20]. This working approach forces odd harmonic components to circulate between the consistent output terminal of the half phase inverter, which can be reduced higher frequency harmonic drawn from the input DC source. DC voltage source of $V_{D C}$ gaining a midpoint 'o'. $L_{\text {in_inv }}$ and $I_{\text {in }}$ are the DC bus component of inductor and current through it. $C_{i n_{-} i n v}$ and $v_{i n}$ are represents the DC bus capacitor and the capacitive voltage on it. $V_{O_{-} M G}$ and $i_{t h e} O_{-} M G$ are the grid voltage and current form the grid LCL lowpass filter. $i_{L_{-} i n v}$ is the current flowing through the grid inductor of $I_{O_{-} M G}$. The phase terminal of a sub-inverter leg formed by $\mathrm{S}_{1}$ and $\mathrm{S}_{2}$ complete input side of the inverter is multi-connection to the DC to DC boost converter [21]. Whereas, the one sub-inverter leg formed by $S_{3}$ and $S_{4}$ are connected to the inverter output grid filter that can be converted DC to AC power with the DC to DC terminal cooperation. The inverter output current and voltage are expected by the following (1) and (2) [19].

$$
\begin{aligned}
& v_{O_{-} M G}=V_{D C} \times \sin (\omega t) \\
& i_{O_{-} M G}=I_{O_{-} M G} \times \sin (\omega t-\varphi)
\end{aligned}
$$

In these equations above, the power factor of the inverter is $\cos \varphi$ and the fundamental grid frequency is $\omega_{f}$. Then $i_{L_{-} i n v}$ and $V_{a b}$ is determined by following (3).

$$
V_{a b}=V_{a}-V_{b}
$$

(3) recommends that only $V_{a}-V_{b}$ requirements to be determined, where the values of $V_{a}$ and $V_{b}$ are unconstrained. If the DC bus distorted ripple current is ripple free, at that point the inverter input source should only be proposed the continuous power, and the grid lowpass filter of the capacitor must be twisted all the vibrating power. Reliable with the change power of the S-PSI, the determination of $I_{\text {in_inv }}, i_{C}$ and $V_{C}$ can be measured as the following equation.

$$
\begin{aligned}
& I_{\text {in_inv }}=\frac{V_{O_{-} M G} I_{O_{-} M G} \cos (\varphi)}{2 V_{D C}} \\
& V_{C}=V_{\text {in_ } C_{-} O}+\frac{V_{a b} I_{L_{-} i n v}}{4 \omega C_{\text {in }} V_{\text {in_ } C_{-} O}} \sin (2 \omega t-\alpha+\beta) \\
& i_{\text {in_C }}=\frac{V_{a b I_{L_{-} i n v}}}{2 V_{\text {in_ } C_{-} O}} \times \cos (2 \omega t-\alpha+\beta)
\end{aligned}
$$


In these equations above, $V_{\text {in__ }} C_{-}$is the input source DC bus component in $V_{C}$. In the letter case, the cancellation distortion harmonic frequency depends on the add number of interleaving angle and interleaved phases are utilized [1, 20]. Therefore, the carrier frequency of each switch's half phase inverter in the interleaved switching mechanism is lower whereas keeping the equal input current quality that can be developed reduce to switching loss of the inverter. The inverter DC bus inductor of $L_{\text {in_inv }}$ is almost to zero when avoiding the cancellation distortion frequency in $I_{i n}$. where, $V_{a}$ and $V_{b}$ are gained as the following equations.

$$
\begin{aligned}
& V_{a}=V_{a}-V_{a b} \text { and } V_{b}=V_{D C} \\
& V_{a}=V_{D C}+V_{a b} \times \sin (\omega t+\beta)
\end{aligned}
$$

Figure 3 demonstrates the main waveforms of the S-PSI based on as shown in (1), (5), (7) and (8). The inverter DC ripple voltage is kept insignificant by correctly designing the inverter input DC bus capacitance.

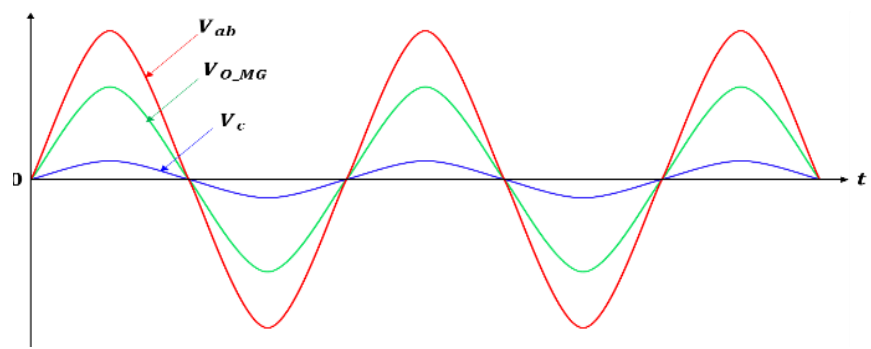

Figure 3. Main voltage waveforms of the S-PSI [1]

The predictable illustrates of the duty cycles of inverter upper switches which are $S_{1}$ and $S_{3}$ as shown in Figure 2 (a). Hence, the flywheel diodes like $D_{1}$ and $D_{3}$ expressed by the following (9) and (10).

$$
\begin{aligned}
& D_{1}=\frac{V_{D C}}{V_{\text {in_ } C_{-} O}} \\
& D_{3}=\frac{V_{D C}}{V_{\text {in_c } O}}+\frac{V_{a b}}{V_{\text {in_ } C_{-} O}} \sin (\omega t+\beta)
\end{aligned}
$$

Based on the duty factor of the half phase inverter upper switch of $S_{3}$, the currents flowing through each switch is assumed as the following Equations. When avoiding the even frequency harmonics distortion. The current reference directions are calculated in Figure 2.

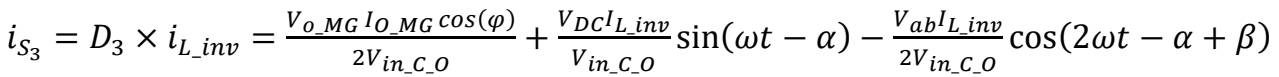

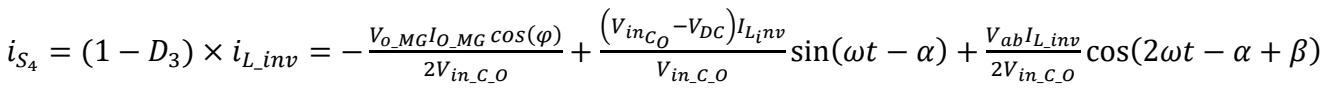

$$
\begin{aligned}
& i_{S_{1}}=i_{C}+i_{S_{3}}=\frac{V_{O_{-} M G I_{O} M G} \cos (\varphi)}{2 V_{\text {in__ } C_{-} O}}+\frac{V_{D C} I_{L_{-} i n v}}{V_{\text {in__ }} C_{-} O} \sin (\omega t-\alpha) \\
& i_{S_{2}}=i_{S_{4}}-i_{C}+I_{i n_{-} i n v}=\frac{V_{O_{-} M G} I_{O \_} M G \cos (\varphi)}{2}\left(\frac{1}{V_{D C}}-\frac{1}{V_{i n_{-} C_{-} O}}\right)+\frac{\left(V_{i n \_} C_{-}-V_{D C}\right) I_{L_{-} i n v}}{V_{\text {in_- }} C_{-} O} \sin (\omega t-\alpha)
\end{aligned}
$$

In the above mention (11) and (12), the currents flowing through switches like $S_{3}$ and $S_{4}$ mainly comprehend DC bus voltage, critical and even harmonic elements as shown in Figure 2 (b). In the later case, (13) and (14) are represented that the currents flowing through $S_{1}$ and $S_{2}$ as shown in Figure 2 (a) only consist of the inverter input source of DC bus voltage and grid frequency elements. As a result, a CBGSC switches consents to gain the transfers functions vital for the proposed design of the S-PSI control of the different parameter of the grid-connected power system $[14,19]$. The consideration parameters of the inverter

Design and implementation of a series switching SPSI for PV cell to use in carrier... (Tawfikur Rahman) 
with switching controls are set that the dynamic model is same to a circuit voltage source inverter, enchanting into justification the point of the process is operated periodic signals modifications in the time of $50 \mathrm{~Hz}$ as exposed in Table 1.

Table 1. Considered parameters of the S-PSI under literature

\begin{tabular}{lcc}
\multicolumn{1}{c}{ Parameters } & Unit & Value \\
\hline Solar Panel Voltage $\left(v_{P V}\right)$ & $\mathrm{V}$ & 170 \\
DC Bus Voltage $\left(v_{D C}\right)$ & $\mathrm{V}$ & 342 \\
Output Grid Voltage $\left(v_{O_{-} M G}\right)$ & $\mathrm{Vrms}$ & 220 \\
Fundamental Grid Frequency $\left(f_{g}\right)$ & $\mathrm{Hz}$ & 50 \\
DC Bus Inductance $\left(L_{\text {inv }}\right)$ & $\mathrm{H}$ & $4 e^{-3}$ \\
DC Bus Capacitor $\left(C_{i n}\right)$ & $\mathrm{F}$ & $570 e^{-4}$ \\
Inverter Side Filter Inductance $\left(L_{\text {inv }} o\right.$ & $\mathrm{H}$ & $6 \mathrm{e}^{-4}$ \\
Grid Filter Inductance $\left(L_{M G}\right)$ & $\mathrm{H}$ & $4.3 \mathrm{e}^{-4}$ \\
Grid Capacitor $\left(C_{f}\right)$ & $\mathrm{F}$ & $20.25 e^{-4}$ \\
Switching Frequency $\left(f_{c}\right)$ & $\mathrm{kHz}$ & 2.5 \\
The resistance of damping $\left(R_{d}\right)$ & $\Omega$ & $2 \mathrm{e}^{-3}$ \\
Duty Cycle $(\mathrm{D})$ & $\%$ & 85 \\
\hline
\end{tabular}

\section{DESIGN PROCEDURE OF A SWITCHING GATE CONTROLLER}

All switching modulation topologies applicable to S-PSI can be utilized in CBGSC with PWM system because switches pulse synchronizes half phase inverter make their outputs independently. In order to reach high efficiency, however, synchronous unpredicting PWM, which combine one phase in every switching interval period, is desirable in this case. This PWM system may be avoided inverter switching the phase terminal with the optimum current magnitude, then also eliminates switching the phase terminal going over zero crossing thus eliminates commutation disappointments. An evaluation between CBGSC with PWM system and other PWM methods, which is a sinusoidal carrier pulse with modulation and space vector modulation for single-phase two-level switching inverter was familiar in [9]. The author [15] described that CBGSC with PWM system not only decreases switching frequency loss, but also the input DC current ripple for series switching type of SPSI.

Figure 4 denotes the CBGSC with PWM for S-PSI that is divided into two steps. The step one upper part is te inverter switches control that switches the inverter power modification, and the other step lower is converter control that is in control of the inverter source voltage boosting. Whereas according to Figure 4, $G_{\mathrm{PI}(s) \text { and } G_{\mathrm{MAF}(s)}}$ are the proportion-integral (PI) and the moving average filter. The inner current loop regulator is complicated to accomplish the DC bus current waveform. The PI controllers are expected by two loops such as $G_{\mathrm{PI}-\mathrm{V}(s)}$ and $G_{\mathrm{PI}-\mathrm{I}(s)}$, respectively. The outer loop regulator of the output signal is the reference of the inner loop which is defined as $I_{i n \_i n v}^{\prime}$.

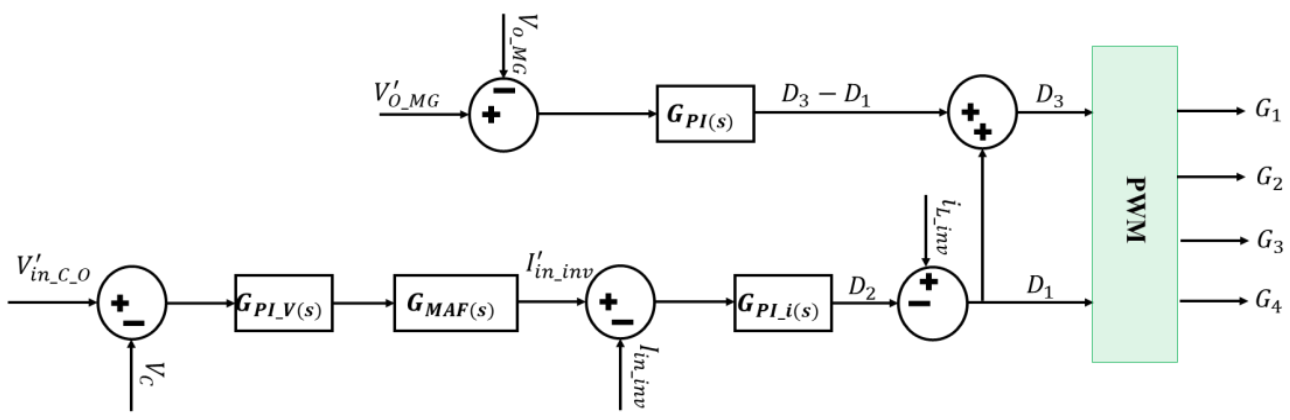

Figure 4. CBGSC scheme of an S-PSI [13]

As mentioned earlier, a few numbers of higher frequency harmonics in the DC bus capacitor voltage of $\mathrm{V}_{\mathrm{C}}$. The even frequencies harmonic elements are fed into the PI regulator of $G_{\mathrm{PI}-\mathrm{V}(s)}$, and better-quality by it. Then a large amount of even harmonic frequency distortion element is seemed in $I_{\text {in_inv }}^{\prime}$. Finally, over the inner loop regulator, there is happen an abundance of low add harmonic frequency distorted in the inverter source current of $I_{i n \_i n v}$ whereas no stages are employed. To reduce the low frequency harmonic distortion 
components such as $I_{\text {in_inv }}^{\prime}$ and $I_{\text {in_inv }}$, the open-loop rise of outer loop current at $2 f$ is decreased. A moving average filter is utilized for eliminating harmonic frequency distortion and its various harmonics in DC bus current reference $I_{\text {in_inv }}^{\prime}$. Additionally, it is applied to the outer voltage loop regulator which can be defined as shown in (15) in s-domain [14]:

$$
G_{\mathrm{MAF}(s)}=\frac{1-e^{-s N_{s} T_{s}}}{s N_{S} T_{S}}
$$

Where, $f_{s}$ is the sampling frequency, $T_{s}=10 \mu \mathrm{s}$, is the sampling time of switching, and $N_{s}$ is the samples number are expected by the filter in a fundamental period. The small-signal similarity circuit and control block diagram of S-PSI is represented in Figure 5. The open loop transfer functions that relay the grid filter inductor current with the duty cycle of $G_{i_{O_{-}} d(s)}$ and the inverter output voltage with the duty cycle $G_{\text {Vo_d }(s)}$ are kept from the S-PSI dynamic models denoted.

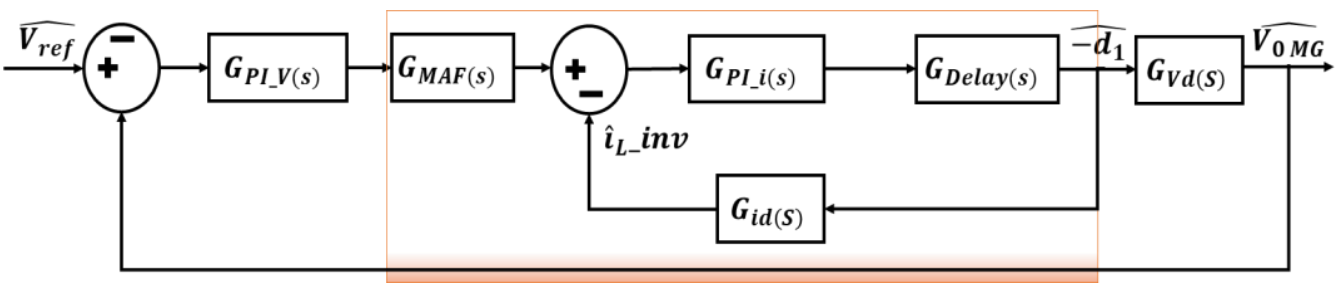

Figure 5. Input boost DC to DC converter control scheme [1]

According to Figure $5, \mathrm{D}_{1}$ is the duty cycle of the two-level switch of $\mathrm{S}_{1}$; $\mathrm{R}_{L_{-} i n v_{-} D}$ means the equivalent load on DC bus voltage that can be known as $\mathrm{R}_{L_{-} D}=\mathrm{V}_{\text {in_C } C_{-} O}^{2} \div V_{O_{-} M G} I_{O_{-} M G} \cos (\varphi)$; the input filter equivalent series resistors (ESRs) are signified such as $\mathrm{R}_{L_{-} \text {in }}$ and $\mathrm{R}_{C_{-} i n}$. The variables with ' $\wedge$ ' is the small trepidations from their steady-state stabilities. Then the transfer functions are offered in (16) and (17) [20]. The $\frac{\widehat{V} C}{\widehat{d_{1}}}$ is represented the duty factor of the input DC bus current transfer function are calculated as:

$$
\begin{aligned}
& G_{V O \_} d(s)=\frac{\widehat{V_{C}}}{\widehat{d_{1}}}=\frac{V_{D C}\left(1+s R_{C \_i n} C_{i n v}\right)\left[1-\left(s L_{i n v}+R_{L \_i n v}\right) /\left(D_{1}^{2} R_{L \_}\right)\right]}{G(s)}
\end{aligned}
$$

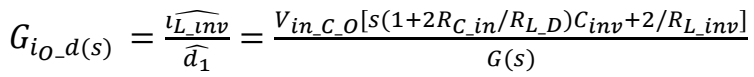

In the mention above Equations, $\mathrm{G}_{\text {Delay }}(s)$ is the digital CBGSC delay effect and it is determined as $\mathrm{G}_{\text {Delay }}(s)=\mathrm{e}^{-0.1 T_{S} s}$. The open-loop transfer functions of the outer and inner loops are defined as following (18) and (19).

$$
\begin{aligned}
& G_{V O P}(\mathrm{~s})=G_{P I-V(s)} G_{M A F(s)} \frac{G_{P I-I(s)} G_{\text {Delay }(s)} G_{V O \_d}(s)}{1+G_{P I-I(s)} G_{\text {Delay }(s)} G_{i O \_} d(s)} \\
& G_{i O P}(\mathrm{~s})=G_{P I-I(s)} \times G_{\text {Delay }(s)} \times G_{i O_{-} d(s)}
\end{aligned}
$$

Firstly, the switching frequency is selected at almost $2.5 \mathrm{kHz}$ to keep the open loop gain at $2 f$ higher enough for the inner loop while the phase margin is expected to higher than $60^{\circ}$ to sustain this loop stable.

\section{GRID COUPLE LOWPASS LCL FILTER DESIGN}

The conventional topological construction is illustrated in Figure 6. This method can be utilized in single-phase PV grid-connected PSI. Where input DC bus voltage is $V_{D C}$, DC bus current is $I_{D C}, S_{1} \sim S_{4}$ four switches made up S-PSI, $L_{i n v_{-} O}, C_{f}$ and $L_{M G}$ are the grid coupled third-order LCL output filter [15]. 


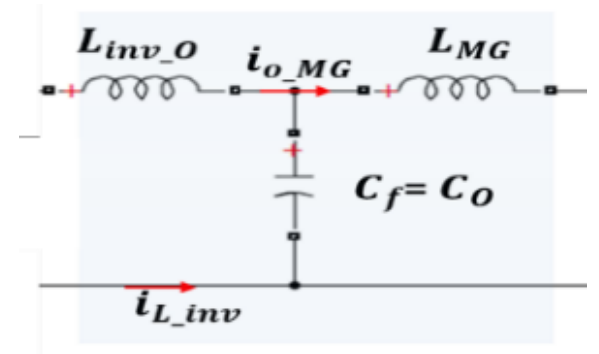

Figure 6. Equivalent circuit of grid couple lowpass LCL filter [1]

The plastic internal resistances of the LCL filter are negligible. The transfer function of the grid coupled inductor current to DC bus voltage is assumed as;

$$
\begin{aligned}
& G_{M(s)}=\frac{G_{i(s)}}{G_{i(v)}}=\frac{1}{L s} \times \frac{\left(s^{2}+R_{d} C_{f} Z_{L C}^{2}+Z_{L C}^{2}\right)}{\left(s^{2}+R_{d} C_{f} \omega_{R E S}^{2} S+\omega_{R E S}^{2}\right)} \\
& P_{\text {Loss }}=3 \times R_{d} \times \sum_{h}\left[i_{\text {inv_o }}(h)-i_{M G}(h)\right]^{2}
\end{aligned}
$$

Then, the resonance grid lowpass LCL filter is made with a higher ripple current. One damping method, a series resistor relates to the shunt capacitor. Where the skin effect is neglected. The grid filter is additional to reduce higher harmonic frequency, then a convention filter quality depends on small reduction associated with what is expected because of oscillation effects. In this case, the DC bus ripple can cause an excess of the filter resonance. Hence, the inductors are correctly designed as DC bus ripple and damped to avoid resonances. However, the damping level is measured by the degradation of the filter efficiency, losses, and cost. Substantial the value of the filter is determined as a percentage of the filter base value by the following (22) and (23).

$$
\begin{aligned}
Z_{\text {Base }} & =\frac{E_{p-p}^{2} p}{P_{a-p}} \\
C_{\text {Base }} & =\frac{1}{Z_{\text {base }} \times \omega_{g f}}
\end{aligned}
$$

Where, $E_{p-p}^{2}$ is the phase to phase voltage, $\omega_{g f}$ is the fundamental grid frequency and $P_{p_{-} p}$ is the active power of the S-PSI. The filter resonant frequency is shown to the switching frequency value calculated as the given (24).

$$
\omega_{R E S}=k \times \omega_{S W}
$$

Where, the resonant frequency of $\omega_{R E S}$, the factor expresses of $\mathrm{k}$ and the switching frequency of $\omega_{S W}$. Consequently, at the switching frequency of the S-PSI output side harmonic voltage is $V_{i n v_{S w}}(h) \neq$ 0 and at the switching frequency of the grid harmonic voltage is $V_{M G_{s w}}(h)=0$. The DC bus current ripple flowing through the inverter output side into the microgrid side are calculated by the following (25).

$$
\frac{i_{M G}}{i_{i n v_{-} o}}=\frac{Z_{L C}^{2}}{\left|\omega_{R E S}^{2}-\omega_{S W}^{2}\right|}
$$

Hence, $\omega_{S W}^{2}=4 \pi^{2} f_{S w}^{2}, \omega_{R E S}^{2}=L_{T} Z_{L C}^{2} / L_{i n v}, f_{S w}$ is the switching frequency and $h_{s w}=\omega_{s w} / \omega_{n}$ is the witching harmonic order. The ripple current presented by the third-order filter is actual only if the LCL is correctly damped.

Finally, the first order, low order, and the higher order frequency harmonic currents get in decomposing the inverter output current. The ripple current is reduced because of inverter side coupled inductor which the flow through current. In the latter case, the filter capacitance is structuring a small amount of resistance to high order frequency harmonic, but the filter inductance is structuring high resistance, therefore the highe order frequency harmonic through of the filter capacitance 


$$
T H D=\frac{\sqrt{\sum_{h=2}^{50} i^{2}(h)}}{i(1)}
$$

At that point the port current of the first order and low order frequency harmonic flow through grid side filter inductance into a power grid. The resulting concert issues are utilized to validate the output microgrid filter efficiency, whereas the first three are low switching frequency pointers and the last two are high switching frequency pointers [3].

\section{S-PSI GRID SYNCHRONOUS METHOD}

To find out the proper phase angle of grid and inverter circuit, zero crossing-based circuits has been designed, with the required fundamental frequency, as shown in Figure 7. In the first step, grid reference signal such as voltage $\left(v_{a}^{\prime}\right.$ and $\left.v_{b}^{\prime}\right)$ and current $\left(i_{a}^{\prime}\right.$ and $\left.i_{b}^{\prime}\right)$ and DC bus reference signal such as $v_{d c}$ and $i_{d c}$ are taken to the sample circuit. Then, this sample circuit makes two types of signals such as DC sample voltage which are operated the DC component circuits and sample signals which are controlled the zero-crossing circuit [22]. The zero-crossing circuit has been designed in such a way that it can detect the zero-crossing point of phase angle and generate zero-crossing samples which are $Z_{a}$ and $Z_{b}$.

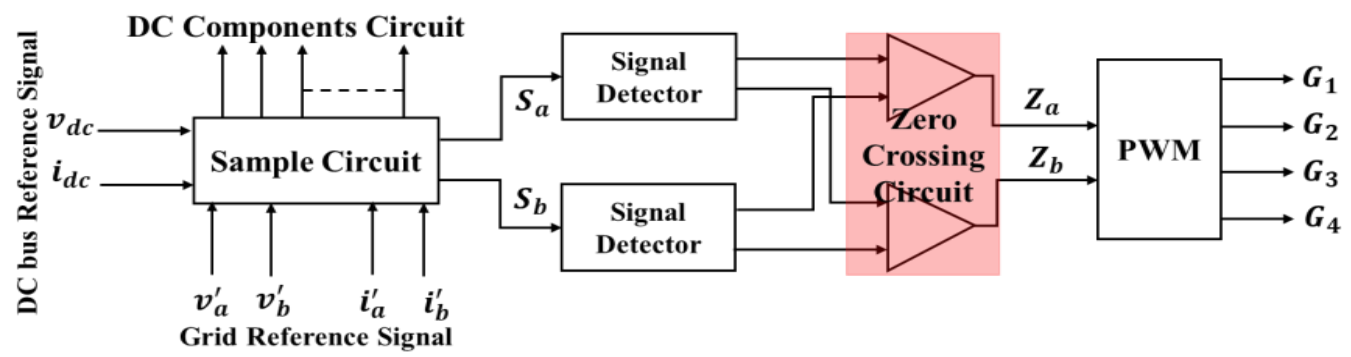

Figure 7. Zero crossing block diagram

Finally, these signals are passed through the PWM generator that can generate four pulses such as $G_{1}, G_{2}, G_{3}$ and $G_{4}$ by utilizing two zero-crossing sample signals [18]. Zero crossing is utilized to identify the phase angle as shown in Figure 8.

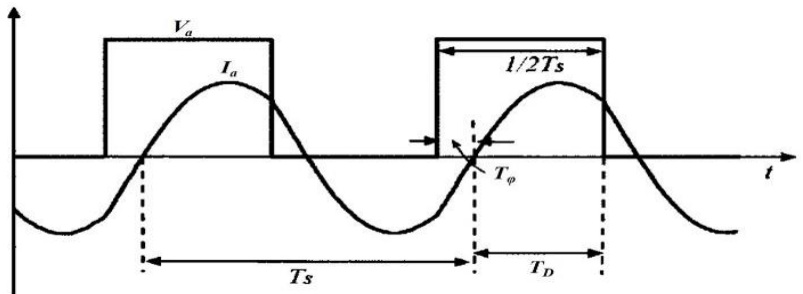

Figure 8. Half phase PSI voltage and current [22]

In the zero-crossing circuit, IGBT switching pulse has changed from the turn OFF to the turn ON state, which means changing to a high state from the low state to detect the desired phase. (27) shows that a sinusoid is a consideration under the signal.

$$
V(t)=V \sin \left(\omega_{o} t\right)=V \sin \left(2 \pi f_{o} t\right)
$$

Then, the phase current has been swept from $0^{\circ}$ to $90^{\circ}$.

$$
T_{D}+T_{\varphi}=\frac{T_{S}}{2}
$$


$T_{D}=\frac{T_{S}}{2}-\varphi_{\text {ref }} \times \frac{T_{S}}{360^{0}}$

Where $T_{D}$ is the control variable, the phase angle command to current phase is $\varphi_{\text {res }}$ and time response of currenthe t phase is $T_{\varphi}$.

$$
\begin{aligned}
& \alpha=\frac{\varphi_{r e f}}{90^{0}} \\
& T_{D}=\frac{T_{S}}{2}(2-\alpha) \\
& T_{D}[\mathrm{n}]=\frac{T_{S}[n-1]}{4}(2-\alpha[\mathrm{n}])
\end{aligned}
$$

Again,

$$
\begin{aligned}
& \alpha[\mathrm{n}]=\frac{\varphi_{\text {ref }}[n]}{90^{0}} \text { When, } 0 \leq \alpha[\mathrm{n}] \leq 1 \\
& T_{D}[\mathrm{n}]=\frac{T_{S}[n-1]}{4}\left[\frac{\left(2^{S}-1\right)+\left(2^{S}-1-\alpha_{1}[n]\right.}{2^{S}}\right]
\end{aligned}
$$

Where $S$ is the number of samples in the zero-crossing phase command and $\alpha_{1}[\mathrm{n}]=0$ parallels to $0^{\circ}$, while $\alpha_{1}[\mathrm{n}]=2^{S-1}$ parallels to $90^{\circ}$. For a large $\mathrm{n}$, this error can be avoided.

\section{SIMULATION AND RESULTS AND DISCUSSION}

For the S-PSI, CBGSC with PWM method is used to synchronize the phase and frequency and reduce the switching loss. At first, reference sinusoidal signals are created utilizing a sinusoidal oscillator circuit. Therefore, the phase difference is $120^{\circ}$ to the signal among the sinusoidal waves is created utilizing the phase shifter circuits. In this case, the triangular carrier wave is produced by a triangular wave circuit as shown in Figure 9. At that point, separate comparator circuits are made to utilize two switching signals such as $G_{1} \& G_{3}$ and utilizing two inverting circuit signals which are $G_{2} \& G_{4}$ are produced and these pulses switching signal are operated to IGBT of the S-PSI. If the control signal is greater than zero, switch $S_{1}$ is turned "ON" as a selection switching polarity in the grid cycle switching gate signals, IGBTs switches $S_{1}$ and $S_{4}$ are switched concurrently in this synchronous control mode, also $S_{3}$ and $S_{2}$ is inactive. Therefore, the synchronous gate pulse signals $G_{1}$ and $G_{3}$ are low. In the negative half cycle, if the reference control signal is higher than zero, $S_{3}$ is turned "ON" as a selection switching polarity in the half cycle of the grid synchronous gate pulse signals and IGBTs switches $S_{3}$ and $S_{2}$ switched simultaneously in this synchronous control mode.

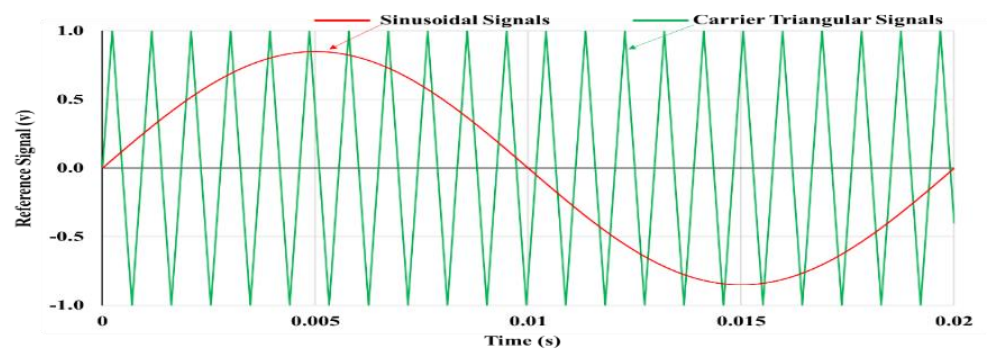

Figure 9. Reference sinusoidal and carrier triangular signal waveforms

So, the other switches $S_{1}$ and $S_{4}$ are inactive and $G_{3}$ and $G_{2}$ are low. The synchronous pulse signals produced, and its pattern is illustrated in Figure 10 that provide an idea switching of S-PSI. 


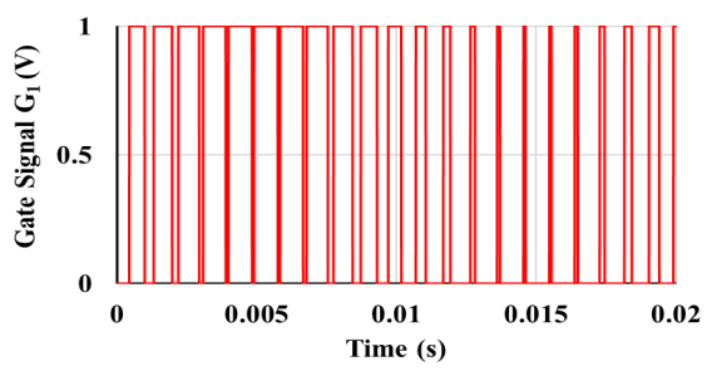

(a)

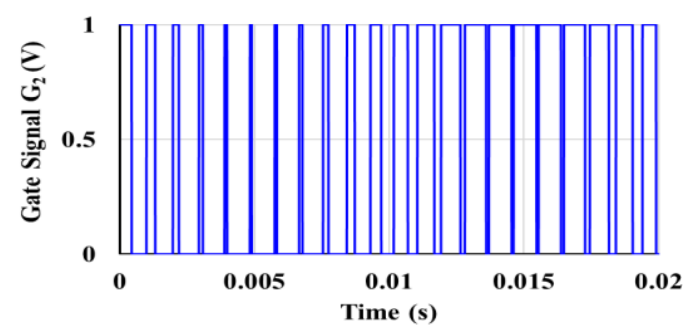

(c)

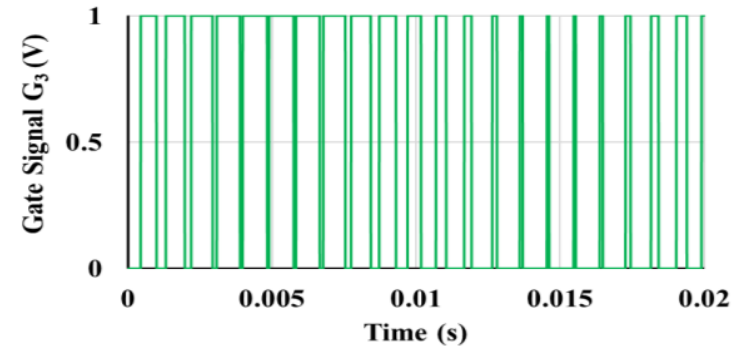

(b)

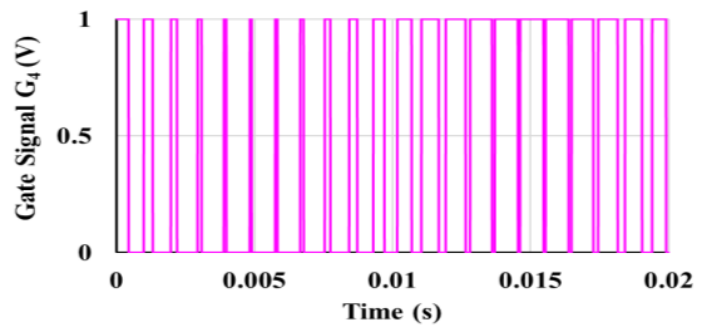

(d)

Figure 10. Separate comparator circuits signals $\left(G_{1}, G_{3}, G_{2}\right.$ and $\left.G_{4}\right)$ for SPSI

The simulated results are compared with the concert of the S-PSI utilizing a CBGSC which is turned to give the maximum grid voltage. The grid rated line to line RMS voltage is $230 \mathrm{~V}$, the DC to DC output source voltage is $\pm 342 \mathrm{~V}$, the modulation index is $85 \%$, the delay is $20 \mu \mathrm{s}$, the sample is $4 \mathrm{k} /$ cycle and other parameters are considered. The outer voltage loop parameters of the DC to DC converter are $k_{i u_{-} 1 s}$ of 1.35 , $k_{p u_{-} 1 s}$ of 0.3 and the MAF is denoted as (15) whereas $N_{s}$ is 159 . The inner loop current parameters are $k_{i i_{-} 1 s}$ of 0.99 and $k_{p i \_1 s}$ of 0.007 . in addition, the synchronous control parameters of the voltage loop are $k_{i_{-} 1 s} V_{C_{-} O_{-} i n v(1 s)}$ of 1 and $k_{p_{-} 1 s} V_{C_{-} O_{-} i n v(1 s)}$ of 0.4 .

Figure 11 demonstrations that the IGBT step response waveform for the initial condition of the SPSI when only CBGSC is assumed for the dual control loop without outer loop voltage. From Figure 8 , it is found that the switching delay of $10 \mu \mathrm{s}$ scheming to a positive response makes a loss development to the switching delay in $20 \mu \mathrm{s}$. Figure 12 depicted that the DC to DC output waveform of the input DC bus voltage is around $342 \mathrm{~V}$ using dual converters.

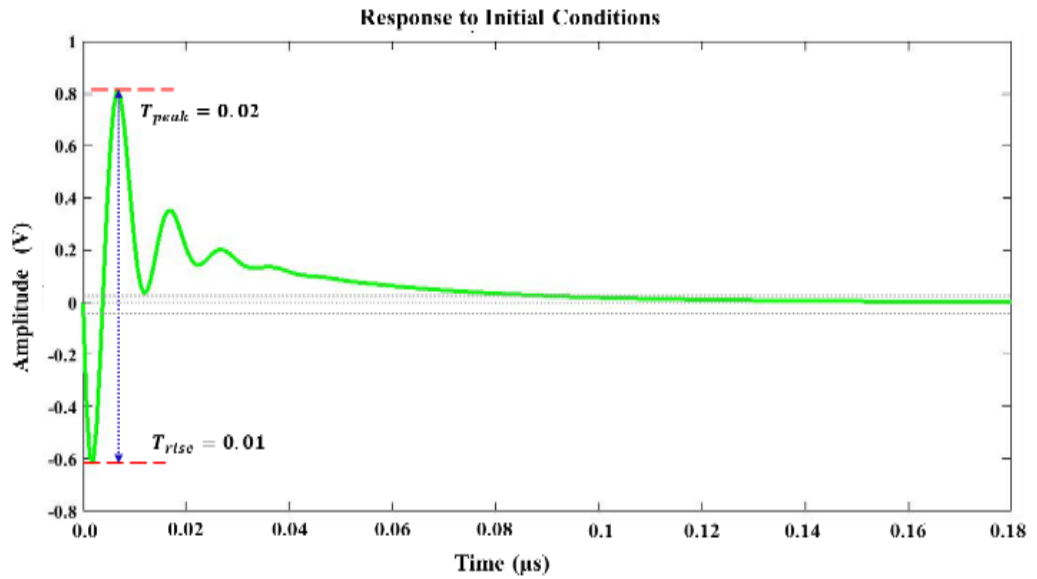

Figure 11. The step response waveform of the IGBT switch to the initial condition 
The parameters for switching power loss of the S-PSI is close to but slightly greater than half of the one in the traditional inverter. The inverter has a high input DC bus ripple current which may lead to a larger switching loss of the IGBTs. The power losses are, individually, considered such as the DC bus inductor ESR of $0.54 \Omega$, DC bus capacitor ESR of $0.216 \Omega$, the input DC side inductor of $4 \mathrm{mH}$ and the input DC bus capacitor of $578 e^{-4} \mathrm{~F}$. S-PSI without filtering condition, the control parameters of the switches in simulated which are operated to verify the theoretical equations and deliver the determined signal as represented in Figure 13 and Figure 14.

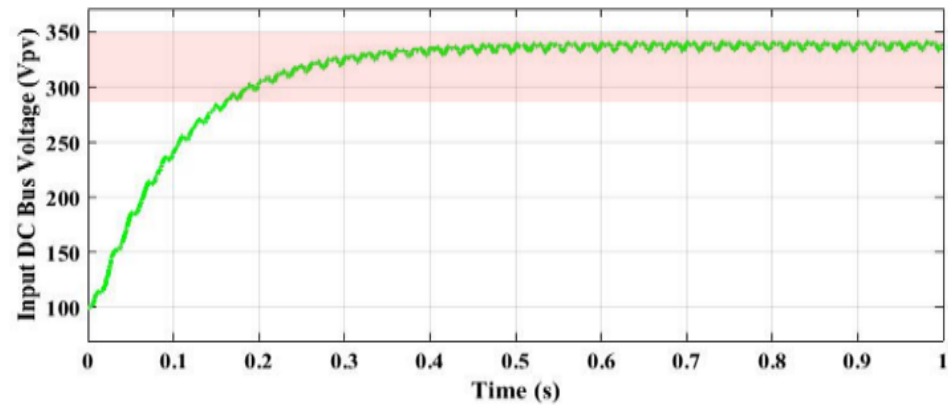

Figure 12. DC to DC converter output DC bus voltage waveform

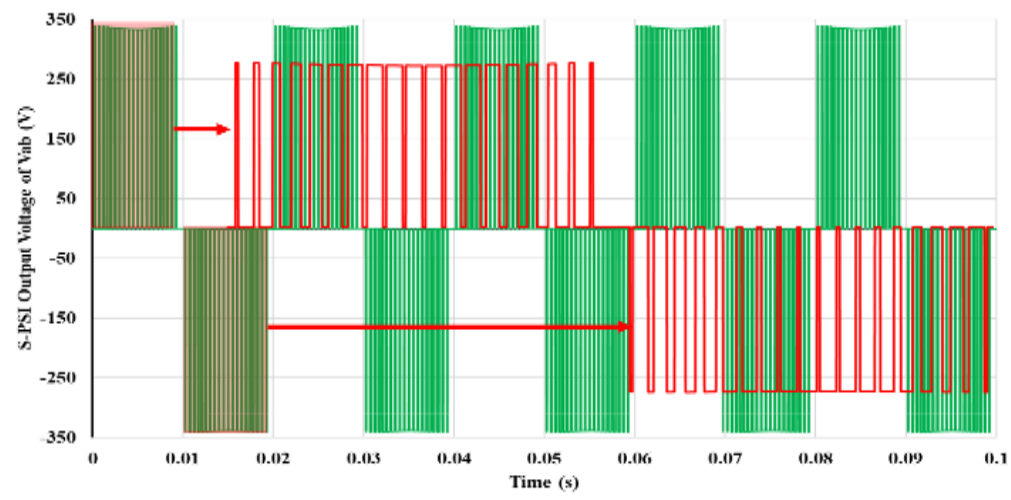

Figure 13. SPSI output voltage waveform without filtering condition [1]

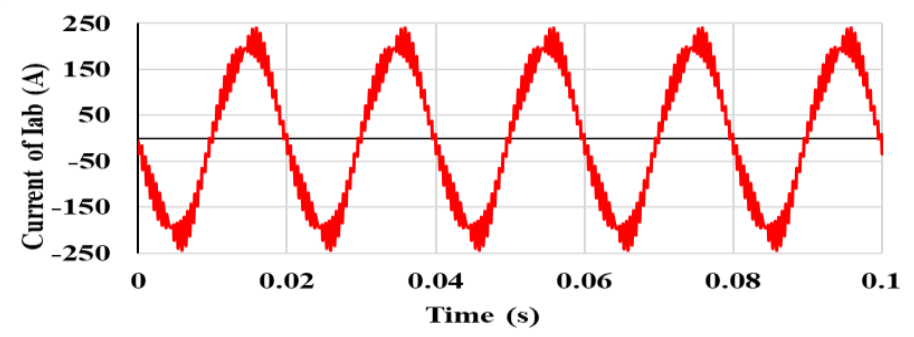

Figure 14. S-PSI output distorted current waveform without filtering condition [1]

From Figure 13 and Figure 14 the steady-state analysis of the S-PSI output voltage waveforms, it is noticed that the output voltage is a carrier-based synchronous PWM signal that pulse amplitude is almost $680 \mathrm{~V}_{p p}$ and the current is almost $400 \mathrm{~A}$ peak to peak. As a result, the simulated results have a great agreement with the achieved results utilizing theoretical and simulated. In the latter case, the dynamic analysis is evaluated by utilizing a step response in the voltage and current reference during the filtering 
condition mode. The inverter output distorted squire wave signals are passed through a grid lowpass LCL filter that can be converted to square wave into pure sine wave as represented in Figure 15 and Figure 16.

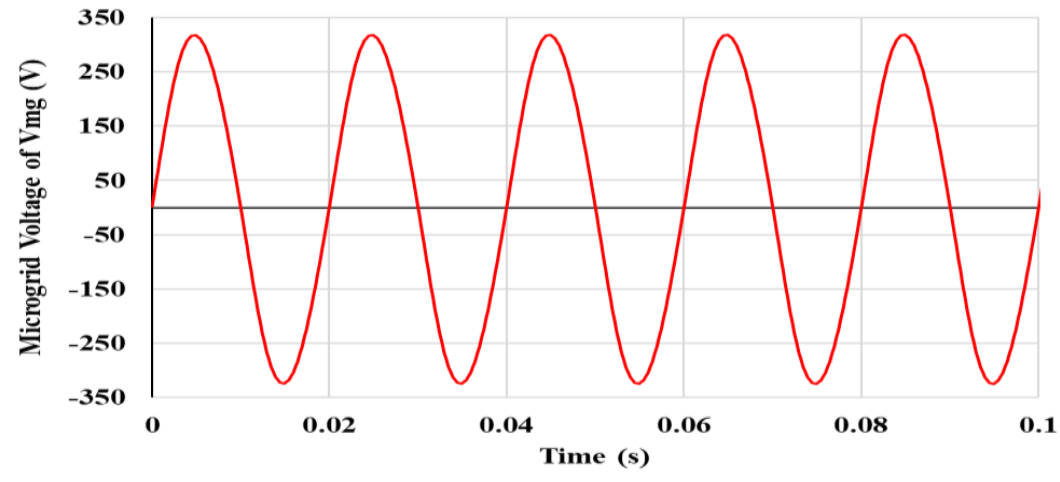

Figure 15. Harmonic free $50 \mathrm{~Hz}$ grid voltage waveform with filtering condition [1]

S-PSI output with filtering condition, it is observed that the grid magnitude is almost $220 \mathrm{~V}_{R M S}$ peak to peak, whereas $11 \Omega$ of the load resistance. Additionally, the grid current waveform is almost $20.18 \mathrm{~A}_{R M S}$ peak to peak, whereas $85 \%$ of the duty cycle, at $t=0.1 \mathrm{~s}$ and 4000 of the sample per cycle.

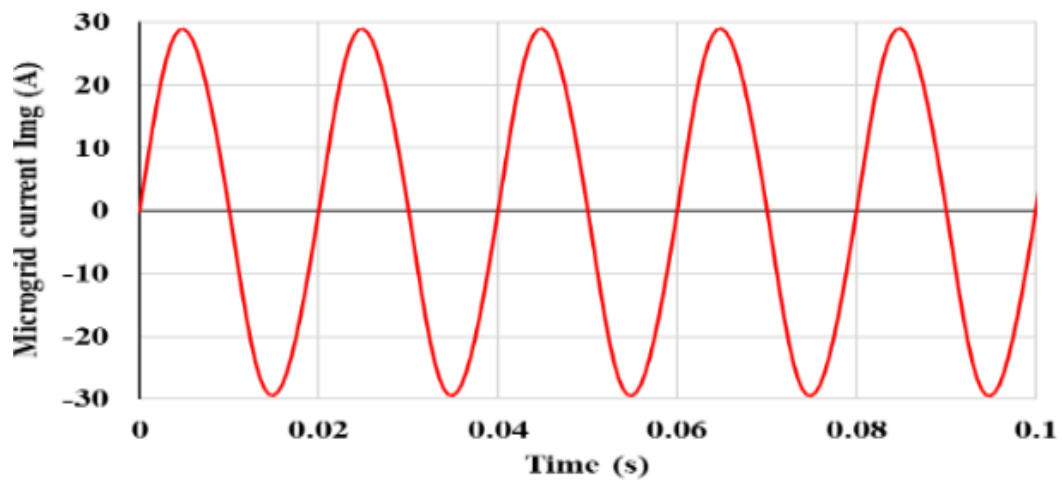

Figure 16. Harmonic free $50 \mathrm{~Hz}$ grid current waveform with filtering condition [1]

Figure 17 demonstrations the FFT for S-PSI output voltage and current waveforms attained by utilizing without filtering signals. The measured THD is represented in Figure 17 (a), without filtering the output voltage THD is around $12.65 \%$ while output current THD is around $12.19 \%$. However, the determined SPSI voltage and current have some low-frequency harmonics distortion, with about a $12.4 \%$ amplitude relative to the fundamental.

With the filtering condition, the FFT of grid magnitudes is very close such as a voltage of $1.98 \%$ and current of $1.98 \%$, respectively, as shown in Figure 17. It is clearly renowned that utilizing grid coupled LCL lowpass filter to reduce THD which is more than $11 \%$ of THD error. 


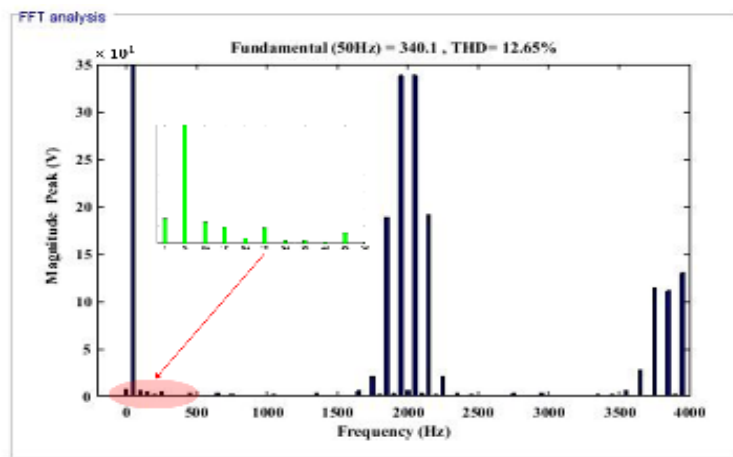

(a)

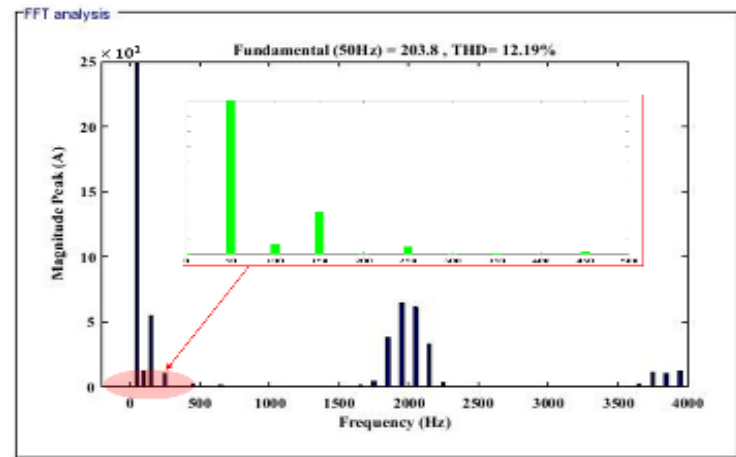

(b)

Figure 17. FFT analysis of the S-PSI, (a) voltage, (b) current THD waveforms without filtering [1]

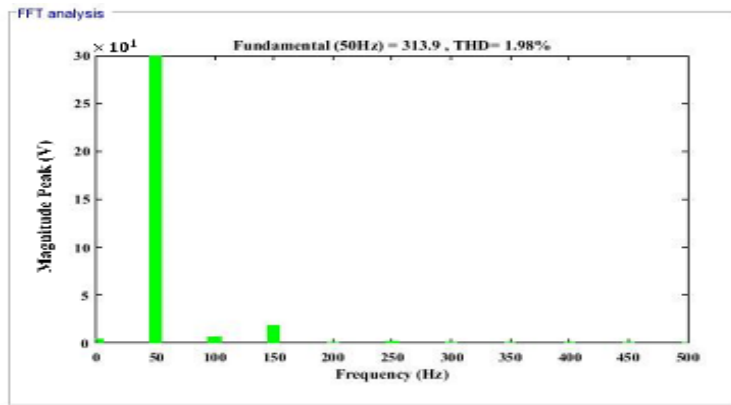

(a)

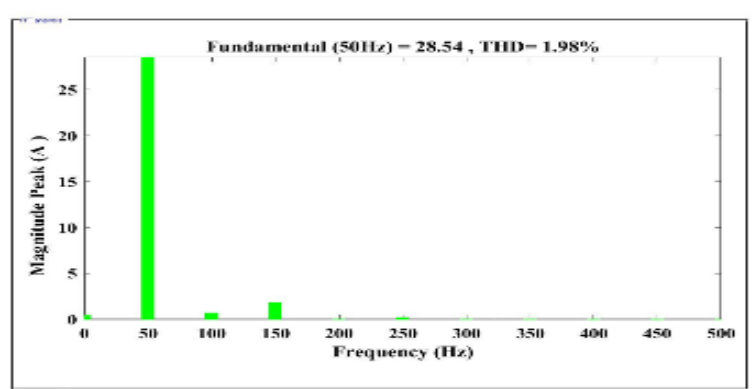

(b)

Figure 18. FFT analysis of the grid, (a) voltage, (b) current THD waveforms with filtering [1]

The sinusoidal signal is the angle of $\Phi$ in degrees that the waveform can be shifted from a positive reference signal point along the zero axes of the horizontal. Generally, the phase shift is the adjacent difference between two or more signals along a sinusoidal waveform and the mutual axis of the same frequency. When grid load resistor of $11 \Omega$ is coupled to a filtering sinusoidal grid voltage supply, whereas the current flowing through the grid load resistor can fluctuate in proportion to the grid voltage which is the voltage and current waveforms are the same phase with each other synchronized. Figure 19 shows the output signal frequency and phase analysis. From the frequency analysis, it is seen that the inverter phase angle is almost synchronized as grid phase, which is approximately $4.67^{\circ}$ lagging of phase angle error whereas the frequency is $52 \mathrm{~Hz}$.

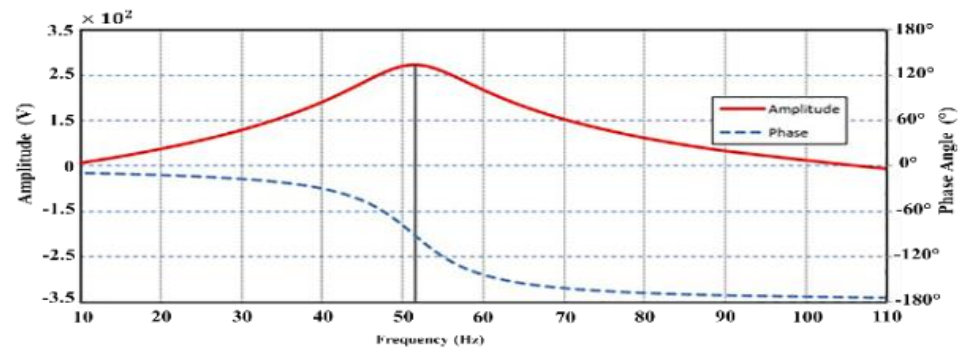

Figure 19. Frequency vs phase analysis of the S-PSI amplitude [1]

The S-PSI phase error is almost the same as microgrid phase due to carrier-based synchronous control in which the phase error is 55\% improvement of the system. Figure 20 shows the Nyquist plot for a second-order system of the S-PSI stability analysis. It is found that the closed loop or open loop transfer function has two zeros in the right half plane which equivalently has two poles. 


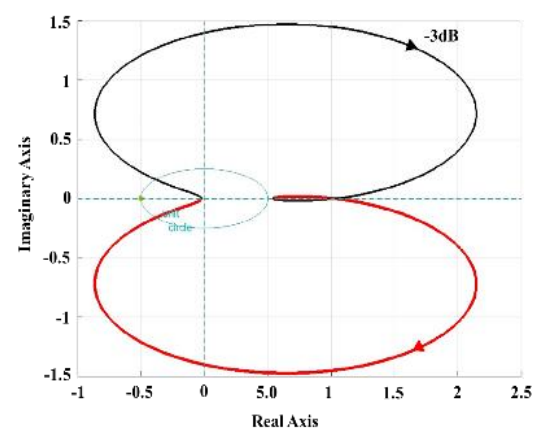

Figure 20. Nyquist plots of the S-PSI [1]

\section{EXPERIMENTAL RESULT VERIFICATIONS}

To establish the analysis above, some experiments are performed on the S-PSI and the experimental results evaluation showed with the S-PSI prototype made, including voltage waveform, THD, and efficiency. The prototype printer circuit bode of the S-PSI is illustrated in Figure 21. The circuit bode dimensions are $12^{\prime \prime} \times 10^{\prime \prime} \times 1.5^{\prime \prime}$, board thickness of $1.55 \mathrm{~mm} \times 50 \mu \mathrm{m}$ and clearance are $10 \mathrm{~mm}$ of top and $1 \mathrm{~mm}$ of the bottom.
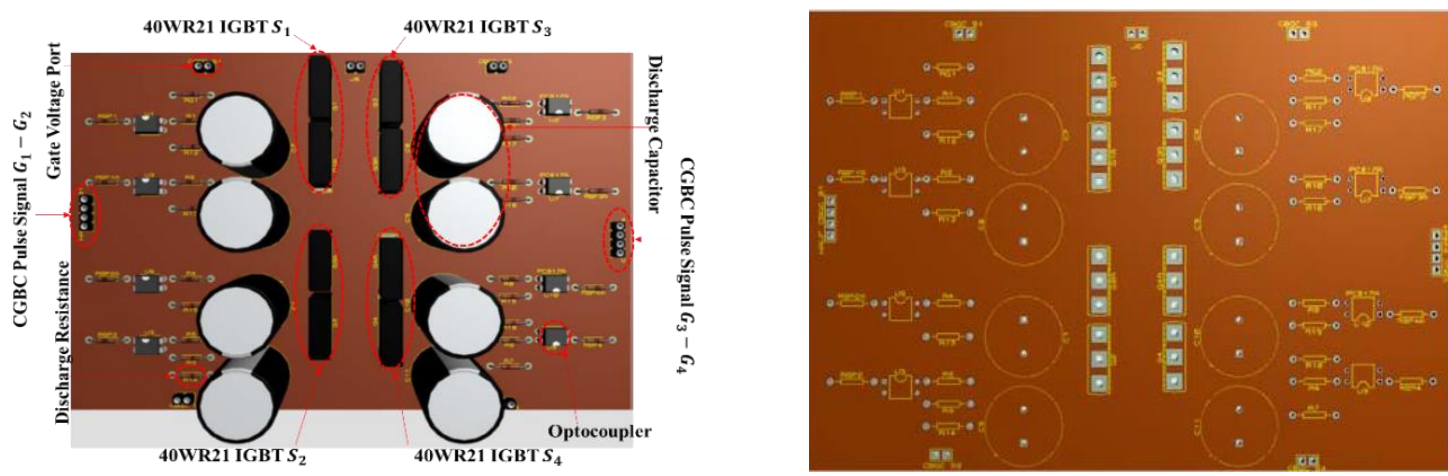

Figure 21. 3D PCB for S-PSI

Experimental waveforms of the inverter controller found at reference active and reactive current are depicted in Figure 20, where $i_{d}, i_{d \_r e f}$ and $i_{q}$ are the regulator reference current, reference active current and reference reactive current. From Figure 22 (a), the reference active current is closed to reference for the current regulator after $0.01 \mathrm{~s}$. While, the reference reactive current is close to zero at $0.001 \mathrm{~s}$. Therefore, the power supply of the reactive from inverter regulator is predictable to increase the voltage lebel of the grid. It occurs in the grid synchronizing after the reference reactive current is needed higher than the making due to the instantaneous influences of an inductive load in the system. If the reference reactive current to the point of interconnection is the likely way of falling the effect of the reference reactive current imbalance.

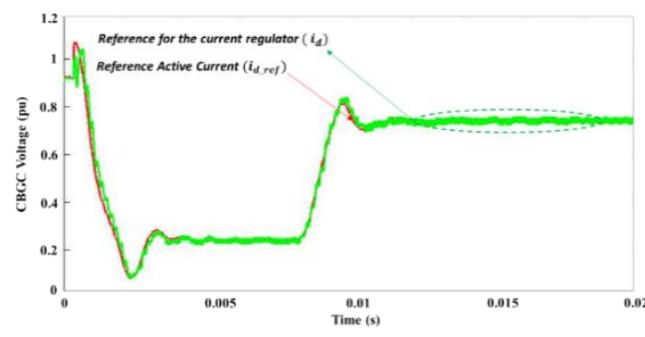

(a)

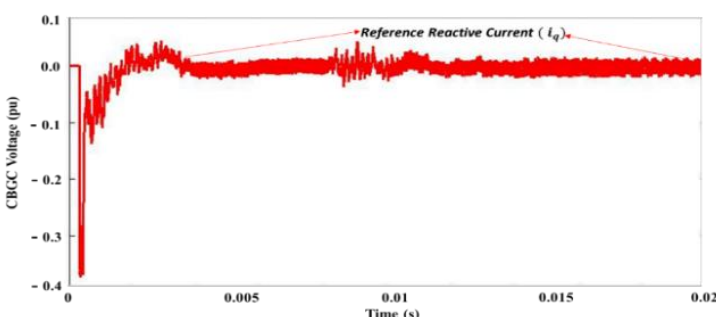

(b)

Figure 22. The controller of the CBGSC reference, (a) active, (b) reactive currents 
Duty Cycle is the time during percentage which that the inverter output signal is in an active state. Figure 23 represents the S-PSI duty cycle effect waveform and inverter input DC bus voltage. Consequently, in Figure 23 (a), it is clearly noticed that the initially the duty cycle is almost $100 \%$ because the output voltage is close to zero after that the time is increased the duty cycle decreased at $0.001 \mathrm{~s}$. The duty cycle is a little bit higher at the time of 0.005 to $0.01 \mathrm{~s}$. Finally, the duty cycle is $85 \%$, whereas at the time of $0.015 \mathrm{~s}$. From Figure 23 (b), it is observed that the input DC bus voltage is almost balanced at the point of $0.01 \mathrm{~s}$ which is around $342 \mathrm{~V}$ and the sum of the reference and mean voltages are equivalent as bus voltage.

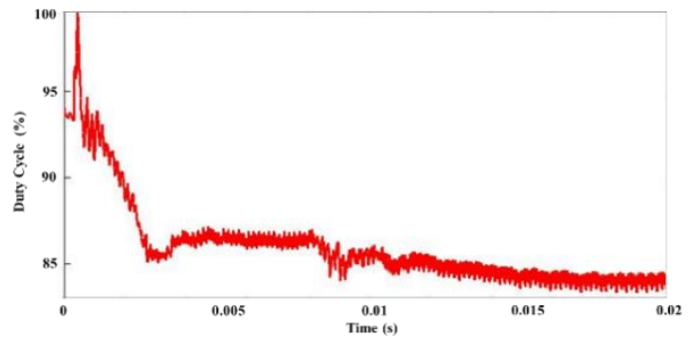

(a)

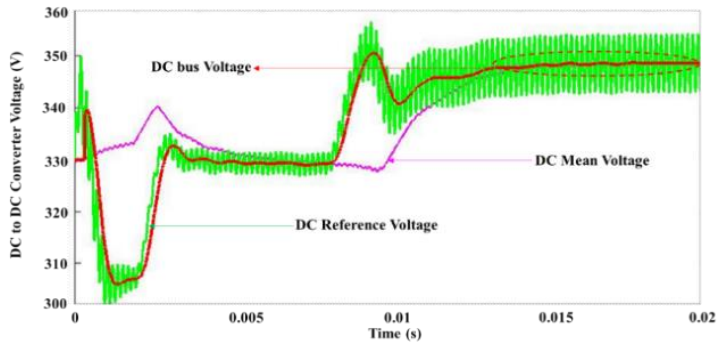

(b)

Figure 23. S-PSI for, (a) duty cycle waveform, (b) DC bus voltage

Experimental output inverter voltage waveform obtained at nominal output voltage without filtering is demonstrated in Figure 24 (a), the parallel to the voltages of two half phase terminals with respect to the input DC bus center point which is induced the voltage difference between these voltages. It is seen that the prototype and simulated results are almost the same which is $350 \mathrm{~V}$ peak voltage.

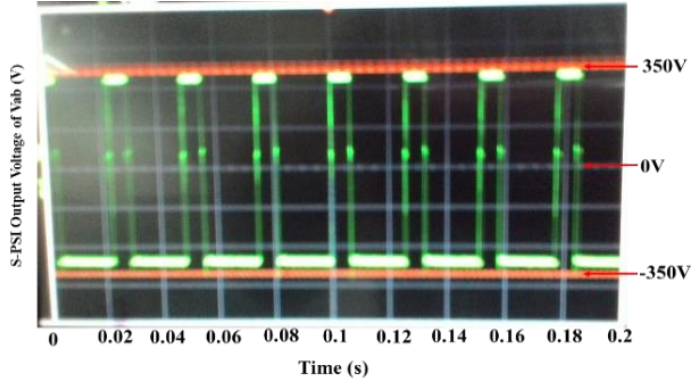

(a)

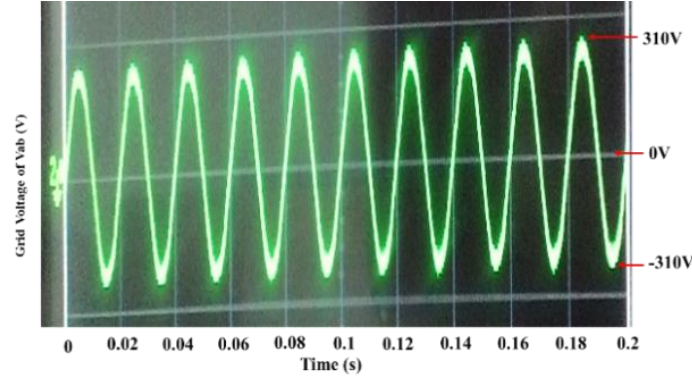

(b)

Figure 24. The Experimental voltage waveform for, (a) without filtering S-PSI, (b) with filtering grid

As observed, Figure 24 (b) is represented by filtering condition, while the grid line to line voltage is around $310 \mathrm{~V}$ peak which is almost equal as a simulated result. In addition, the grid inverter current is nearly sinusoidal and grid phase voltage is depicted to excellently clamp their process to the positive and negative input DC bus rails during the period after the corresponding grid phase currents are close to zero. However, the FFT analysis of the prototype S-PSI voltage waveforms without and with filtering condition is shown in Figure 25. The measure voltage THD at without filtering is about $14.6 \%$ and with filtering is $2.30 \%$ which are the same as simulated results.

Table 2 represents the sets of simulated and prototype results are established as produced from the point prediction and the goal of optimizing the overall system conversion efficiency with decreased higher frequency harmonic distortion and improved phase synchronize. It is clearly seen that the dynamic response of the SPSI system has been tested by the step of the altering grid resistive load from $87.58 \%$ to $100 \%$. Moreover, is is also found that the SPSI phase angle is $4.67^{\circ}$ lagging whereas the other parameters are 
consideraded in this case. Consequently, the optimumized value is gained approxmetlly $97.02 \%$ of the overall system efficiency.

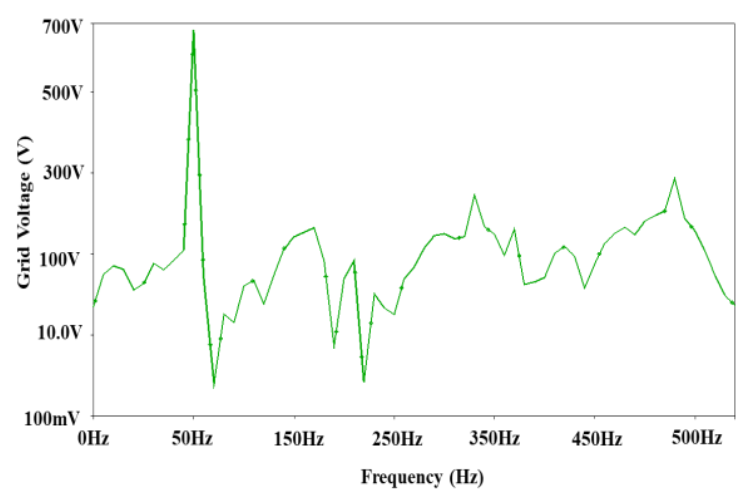

(a)

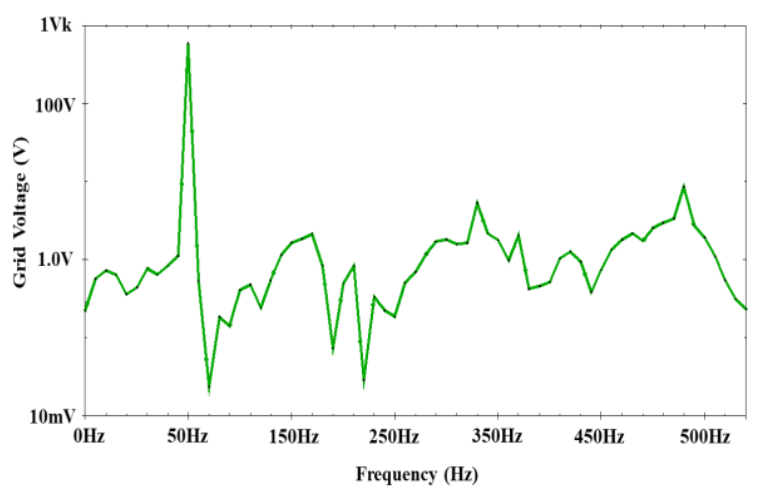

(b)

Figure 25. FFT for S-PSI output voltage waveforms, (a) without filtering, (b) with filtering conditions

Table 2. Comparison between S-PSI and benchmark results

\begin{tabular}{cccccccc}
\hline Switching Freq. & Duty Cycle & Input Voltage & Output Voltage & THD & Phase Angle & Efficiency & Reference \\
\hline $\mathrm{kHz}$ & $(\%)$ & $(\mathrm{V})$ & $($ Vrms $)$ & $(\%)$ & $\left(^{\circ}\right)$ & $(\eta)$ & \\
15.9 & 50 & 200 & 110 & 3.3 & N/A & 91.2 & {$[19]$} \\
2.65 & 85 & 170 & 220 & 1.98 & 4.67 & 97.02 & S-PSI \\
\hline
\end{tabular}

\section{CONCLUSIONS}

This paper represents the design and prototype implementation of series switching SPSI interleaved CBGSC with PV application, which performances with relations steady-state error, transient response, dynamic response and higher frequency harmonics. Form the analysis, it is noticied that the phase angle of the SPSI was developed at $4.67^{\circ}$ lagging which is $55 \%$ lower than the maximum allowable angle (Phase angle $5^{\circ}$ ) as per IEEE standard due to the use of CBGSC. Moreover, the inverter output THD voltage and current waveforms were decreased from $12.42 \%$ of without filtering to $1.98 \%$ of with filtering condition. In the leater case, the proposed S-PSI system recommended that the design switching logic methods were more significant as the maximum acceptable THD is $<5 \%$ as per IEEE standard. It is observed from the simulated and experimental results that the overall system efficiency of the S-PSI is $97 \%$. Finally, the verified results exposed the CBGSC is higher in terms of sinusoidal voltage and current reference tracking with zero steadystate error, slightly slower transient response and very low total harmonic distortion.

\section{ACKNOWLEDGEMENTS}

This research has been supported by the Research Management Centre, International Islamic University Malaysia under the project of RIGS17-006-0581.

\section{REFERENCES}

[1] T. Rahman, S. M. A. Motakabber, M. I. Ibrahimy A. Z. Alam, M. G., Mostafa, and M. W. Rahman, "Carrier Based Synchronous control and performance analysis of an S-PSI using PV for Microgrid Applications," Int. Con. on Com. and Comm. Eng. (ICCCE), 2018 Int. Conf. on IEEE, pp. 1-6, Sep. 2018.

[2] E., Acha, V., Agelidis, O., Anaya, and T. J. E., Miller, "Power electronic control in electrical systems" Elsevier, Dec. 2001.

[3] S. B., Kjaer, J. K., Pedersen, and F., Blaabjerg, "A review of single-phase grid-connected inverters for photovoltaic modules," in IEEE Tran. on Ind. Appl., vol. 41, no. 5, pp. 1292-1306, Sept.-Oct. 2005.

[4] M. Schweizer and J. W. Kolar, "Design and Implementation of a highly efficient three-level T-type converter for low-voltage applications," IEEE Trans. Power Electron., vol. 28, no. 2, pp. 899-907, Feb. 2013.

[5] T. Rahman, S. M. A. Motakabber, M. I. Ibrahimy and M.G. Mostafa, "Simulation and evaluation of a phase synchronous inverter for microgrid system,” ARPN J. Eng. Sci, vol.11, no. 1, pp.1-2, Jan. 2016. 
[6] H., Hu, S., Harb, and N., Kutkut, "A review of power decoupling techniques for microinverters with three different decoupling capacitor locations in PV systems", in IEEE Trans. Power Electron., vol. 28, no. 6, pp. 2711-2726, Jun. 2013.

[7] G., Fontes, C., Turpin, S., and Astier, et al., "Interactions between fuel cells and power converters: influence of current harmonics on a fuel cell stack", in IEEE Trans. Power Electron., vol., 22, no. 2, pp. 670-678, Mar. 2007.

[8] T. Rahman, S. M. A. Motakabber and M. I. Ibrahimy, "Design of a Switching Mode Three Phase Inverter," 2016 International Conference on Computer and Communication Engineering (ICCCE), Kuala Lumpur, 2016, pp. 155-160.

[9] P., Karlsson, and J. Svensson, "DC bus voltage control for a distributed power system, "in IEEE Tran. on Power Electron., vol. 18, no. 6, pp. 1405-1412, Nov. 2003.

[10] M., Davari, and Y. A. R. I. Mohamed, "Robust Droop and DC-Bus Voltage Control for Effective Stabilization and Power Sharing in VSC Multiterminal DC Grids" in IEEE Tran. on Power Electron., vol. 33, no. 5, pp. 4373-4395, May 2018.

[11] M. Z., Hossain, and N. A. Rahim, "Recent progress and development on power DC-DC converter topology, control, design and applications: A review," Ren. and Sust. Ene. Rev., vol. 81, pp. 205-230, Jan. 2018.

[12] Q., Wang, X., Zhang, R., Burgos, D., Boroyevich, A., White, and M. Kheraluwala, "Design and implementation of a two-channel interleaved Vienna-type rectifier with> 99\% efficiency, "in IEEE Trans. Power Electron., vol. 33, no. 1, pp. 226-239, Jan. 2018.

[13] Sun, Y., Liu, Y., Su, M., et al.: "Review of active power decoupling topologies in single-phase systems", in IEEE Trans. Power Electron., vol. 31, no. 7, pp. 4778-4794, Jul. 2016.

[14] T, Rahman M. I., Ibrahimy, and S. M. A., Motakabber, "Synchronization of Output Voltage Waveforms in Phase Synchronous inverter with LCL Filter for Smart Grid Systems," Int. Con. on Sci. and Soc. Res. pp. 6-7, Jul. 2017.

[15] Zhu, G., Wang, H., Liang, B., et al.: "Enhanced single-phase full-bridge inverter with minimal low-frequency current ripple", in IEEE Trans. Ind. Electron., vol. 63, no. 2, pp. 937-943, Feb. 2016.

[16] T. Rahman, "Design of a Phase Synchronous Inverter for Micro-grid Systems," Master dissertation, Kull. of Eng., International Islamic University Malaysia, 2016.

[17] C. C. Gomes, A. F. Cupertino, and H. A. Pereira, "Damping techniques for grid-connected voltage source converters based on LCL filter: An overview," Ren. and Sust. Ene. Rev., vol. 81, pp. 116-135, Jan. 2018.

[18] T. Rahman, S. M. A. Motakabber and M. I. Ibrahimy, "Low Noise Inverter for Poly Phase Microgrid System," 2016 International Conference on Computer and Communication Engineering (ICCCE), Kuala Lumpur, 2016, pp. 172-176.

[19] Shi, Y., Bangyin L., and Shanxu D., "Modelling, control and performance analysis of a single-stage single-phase inverter with reduced low-frequency input current ripple." IET Power Electron., Vol. 11, no. 6, pp. 1074-1082, Jan 2018.

[20] Vitorino, M. A., Alves, L. F. S., Wang, R., et al.: "Low-frequency power decoupling in single-phase applications: a comprehensive overview”, IEEE Trans. Power Electron., vol. 32, no. 4, pp. 2892-2912, Apr. 2017.

[21] T. Rahman, S. M. A. Motakabber, and M. I. Ibrahimy, "A Zero Crossing PWM Controller of a Full Bridge Single Phase Synchronous Inverter for Microgrid Systems," Int. Jou. of Eng. and Inf. Sys. (IJEAIS), vol. 1, no. 6, pp. 20211, Sep. 2017.

[22] S Jaisudha, S Srinivasan, K Gunasekaran, "Bidirectional Resonant DC-DC converter for Microgrid Applications," Int. Journal of Power Electron. and Drive Sys. (IJPEDS), vol. 8, no. 4, pp. 1548-61, Dec, 2017. 